\title{
PERFIL DE RESISTÊNCIA ANTIMICROBIANA DE ESCHERICHIA COLI ISOLADAS DO AÇUDE SANTO ANASTÁCIO, CEARÁ, BRASIL
}

\author{
F.R. Vasconcelos $^{1 *}$, R.H. Rebouças ${ }^{1 * *}$, N.S. Evangelista-Barreto ${ }^{2}$, O.V. de Sousa ${ }^{1 * * *}$, R.H.S.F. Vieira ${ }^{1}$ \\ ${ }^{1}$ Universidade Federal do Ceará, Instituto de Ciências do Mar, Av. Abolição 3207, CEP 60165-081, Fortaleza, \\ CE, Brasil. E-mail: nsevangelista@yahoo.com.br
}

\section{RESUMO}

\begin{abstract}
Este trabalho objetivou caracterizar a resistência antimicrobiana de 43 cepas de Escherichia coli isoladas do açude Santo Anastácio (Fortaleza, CE), durante os meses de janeiro a abril de 2007. As cepas foram submetidas a testes de suscetibilidade a oito antimicrobianos, tendo $67,4 \%$ delas apresentado sensibilidade a todos. Observou-se resistência à tetraciclina (25,6\%), ao sulfazotrin $(18,6 \%)$, ao ácido nalidixíco $(9,3 \%)$ e a ciprofloxacina $(4,7 \%)$. Nenhuma resistência foi observada aos betalactâmicos. Nove (21\%) cepas apresentaram multirresistência, com um percentual de $78 \%$ para resistência cromossômica e 56 \% para resistência plasmidial. A presença de bactérias resistentes pode estar relacionada ao lançamento de antimicrobianos nas águas através de esgotos, sendo que o uso inadequado dessas águas pode comprometer a saúde da população.
\end{abstract}

PALAVRAS-CHAVE: Antimicrobianos, perfil de resistência, águas superficial, E. coli.

\section{ABSTRACT}

RESISTANCE PROFILE OF ESCHERICHIA COLI ISOLATED FROM THE ENVIRONMENT. The aim of this study was to determine the antimicrobial resistance of 43 Escherichia coli strains isolated from the Santo Antonio weir (Fortaleza, CE, Brazil) from January to April 2007. Susceptibility tests performed with 8 antimicrobials indicated that $67.5 \%$ of the strains were susceptible to all of them. Resistance to tetracycline (25.6\%), sulfazotrim $(18.6 \%)$, nalidixic acid $(9.3 \%)$, and ciprofloxacin $(4.7 \%)$ was observed. The strains did not show resistance to betalactamics. Nine strains $(21 \%)$ were multiresistant, the resistance being chromosome (78\%) and plasmid (56\%) mediated. The presence of resistant bacteria may be related to antimicrobials in the sewage discharged into the weir, and the inappropriate use of this body of water may pose human health risks.

KEY WORDS: Antimicrobials, resistance profile, superficial waters, E. coli.

\section{INTRODUÇÃO}

Em regiões com pouco suprimento de água é comum a utilização de açudes como fonte de abastecimento para humanos e animais. Essas águas são susceptíveis à contaminação, em virtude do despejo de fossas e esgotos, dejetos industriais e lixo, contribuindo para o aumento de micro-organismos como os coliformes, Salmonella e Pseudomonas, dentre outros (VIEIRA; FaÇANHA, 1994), colocando em risco a saúde da população consumidora (AMARAL et al., 2006). O uso dos corpos hídricos como receptáculo para efluentes orgânicos aumentou com o crescimento populacional, agravando o declínio das condições sanitárias em diversas comunidades urbanas. Com isso, a descarga de efluentes nos reservatórios tem contribuído para o aumento da contaminação por micro-organismos patogênicos (EsTEVEs, 1998), incluindo aqueles portadores de genes de resistência antimicrobiana (MeIreles-Pereira et al., 2002) mediados por plasmídeos R (BOON; CATTANACH, 1999).

Escherichia coli, principal agente etiológico de infecções entéricas causada pela água e alimentos contaminados, principalmente em grupos populacionais que não dispõem de sistema de saneamento, ou se apresentam vulneráveis como os idosos e crianças imunocomprometidos (VIEIRA et al., 2004), é o indicador de contaminação de origem fecal mais

\footnotetext{
${ }^{2}$ Universidade Federal do Recôncavo da Bahia, Cruz das Almas, BA, Brasil.

*Mestrando em Eng. de Pesca pela UFC.

**Mestre em Engenharia de Pesca pela UFC.

***DCR/CNPq/FUNCAP no Instituto de Ciências do Mar/UFC.
} 
comumente utilizado, pois ocorre em grande número na microbiota intestinal de humanos e animais ( Amaral et al., 2003).

Por outro lado, o estudo da resistência antimicrobiana dos organismos indígenos da água é de suma importância, uma vez que pode indicar o grau de alteração dos ecossistemas pela ação humana, além de servirem de reservatórios para genes de resistência (BOON; CATTANACH , 1999; BAQUERO et al., 2008). A resistência microbiana pode ser transferida por diversos mecanismos, podendo estabelecer-se entre espécies da mesma população ou diferentes populações, tanto da microbiota animal para a humana como vice-versa (NIJSTEN et al., 1993).

Oteste de suscetibilidade a antimicrobianos avalia a sensibilidade dos micro-organismos a diferentes agentes (Meireles-Pereira et al., 2002). Em virtude da complexidade dos mecanismos de resistência, a seleção de drogas apropriadas tanto para o teste de susceptibilidade, quanto para a terapia antimicrobiana, torna-se uma missão cada vez mais difícil, podendo levar ao aumento da morbidade e da mortalidade dos pacientes tratados incorretamente.

Para Moura et al. (2009), érelevante o conhecimento das reais condições dos mananciais superficiais que abastecem as cidades, a fim de contribuir significativamente para a promoção efetiva de planejamentos que visem melhorar a qualidade microbiológica dos referidos mananciais, caso seja necessário. Assim, o objetivo deste trabalho foi determinar o perfil de resistência aos antimicrobianos de cepas de E. coli isoladas nas águas do açude Santo Anastácio.

\section{MATERIAL E MÉTODOS}

Foram testadas 43 cepas de E. coli isoladas de amostras de água provenientes do açude Santo Anastácio (Fortaleza, CE), no período de janeiro a abril de 2007. A identificação das amostras foi confirmada pelo isolamento de colônias características em ágar EMB (Difco) e testes bioquímicos (Indol, Vermelho de Metila, Voges-Proskauer e Citrato) (Mehlman et al.,1984).

O método utilizado no teste de antibiograma seguiu as recomendações do Clinical and Laboratory Standards Institute-CLSI (CLSI, 2007). Utilizaram-se colônias crescidas em meio ágar tryptone soy (TSA - Difco) por $24 \mathrm{~h}$. Posteriormente, foram retirados inóculos das amostras e colocados em $10 \mathrm{~mL}$ de solução salina $0,85 \%$, até atingir a turvação correspondente ao tubo 0,5 da escala McFarland aferida em espectrofotômetro (Micronal, mod. B542). A suspensão bacteriana foi semeada uniformementeem placas contendoágar Müeller-Hinton com auxílio de suabes esterilizados. Após absorção do inóculo no meio por alguns minutos, os discos de antibióticos foram depositados com pinça esterilizada e as placas foram incubadas a $37^{\circ} \mathrm{C}$ por $24 \mathrm{~h}$. Seguido esse período, foi efetuada a leitura dos halos de inibição utilizando-se paquímetro e, de acordo com seus tamanhos, as cepas foram classificadas em sensíveis, intermediárias e resistentes. Todos os ensaios foram realizados em duplicata e os testes foram acompanhados usando-se a cepa padrão E. coli ATCC 25922, cujas variações aceitáveis para as medidas dos halos de inibição encontram-se estabelecidas no CLSI (2007). Os antibióticos testados foram: Ampicilina $(10 \mu \mathrm{g})$, Ácido Nalidíxico $(30 \mu \mathrm{g})$, Cefoxitina $(30 \mu \mathrm{g})$, Ciprofloxacina $(5 \mu \mathrm{g})$, Imipinem $(10 \mu \mathrm{g})$, Nitrofurantoina $(300 \mu \mathrm{g})$, Sulfazotrin $(25 \mu \mathrm{g})$ e Tetraciclina $(30 \mu \mathrm{g})$.

A presença ou ausência de plasmídios- $R$ foi testada para as cepas que apresentaram perfil de multirresistência aos antimicrobianos testados. Como agente de cura foi utilizado o Acridine Orange (AO) na concentração de $100 \mu \mathrm{g} / \mathrm{mL}$. As cepas foram crescidas em caldo Soja Triptona (TSB), incubadas por $24 \mathrm{~h}$ a $30^{\circ} \mathrm{C}$ em estufa bacteriológica. Após esse período, alíquotas de $200 \mu \mathrm{L}$ foram adicionadas aos tubos contendo caldo Luria Bertani (LB) (controle) e aos tubos contendo caldo $\mathrm{LB}+\mathrm{AO}$ que foram logo em seguida incubados em banho-maria com agitação constante por $24 \mathrm{~h} \mathrm{a} 30^{\circ} \mathrm{C}$. As culturas crescidas nesses caldos foram submetidas novamente ao teste deantibiograma frente aos antimicrobianos aos quais haviam apresentado resistência anteriormente para determinação de alteração no perfil de resistência (MolinA-AjA et al., 2002).

O índice de múltipla resistência a antimicrobianos (índice MAR) foi calculado como o número de antimicrobianos ao qual determinado isolado foi resistente sobre o número total testado (oito, nesse caso), multiplicando-se o valor final por 100 para obtenção dos resultados em percentuais (HIRSCH et al., 2006).

\section{RESULTADOS E DISCUSSÃO}

Os resultados do teste de suscetibilidade aos agentes antimicrobianos mostraram que 32,6\% (14) das cepas apresentaram resistência a pelo menos um dos oito antimicrobianos usados. Os rios são considerados os principais receptores de resíduos de antimicrobianos, devido o recebimento de esgotos urbanos, industriais e hospitalares (FUENTEFRIA et al., 2008). Por isso, a presença dessas drogas em águas residuais tem provocado um impacto significativo na seleção de bactérias resistentes e presentes na água e no sedimento (KuMMERER, 2003).

Os antimicrobianos ampicilina, cefoxitina e imipenem apresentaram eficiência de $100 \%$ sobre as cepas (Tabela1). Resultados semelhantesforamencontrados por MARTINHAGO et al. (2008), ao avaliarem o perfil de 
susceptibilidade de E. coli isoladas do Lago Municipal em Cascavel, PR, e diferente de Melo (2006) que relatou resistência a ampicilina de $20 \%$ em $E$. coli isoladas da lagoa do Parque Estadual do Rio Doce, MG. Essa diferença de relatos demonstra que a presença de organismos antibióticos-resistentes ou genes-resistentes na água doce varia de acordo com alguns parâmetros como, por exemplo, proximidade com áreas que utilizam antibióticos, como áreas de cultivo ou esgotos hospitalares, águas poluídas com esgotos industriais, devidoos metais contribuíremnoaumento da resistência antimicrobiana ou, ainda, as diferentes estações do ano, sendo mais frequente o aumento da resistência no período chuvoso (PEAK et al., 2007).

Resistência à tetraciclina e ao sulfazotrin foi observada em 25,6 e 18,6\%, respectivamente, dos isolados (Tabela 1). SCHNEIDER et al. (2009), estudando cepas de E. coli isoladas de águas superficiais em Santa Catarina, relataram resistência a tetraciclina em $28,8 \%$ dos isolados. A tetraciclina é comumente utilizada como umantimicrobiano de primeira linha sendo, frequentemente, utilizada previamente à determinação do perfil de resistência do patógeno (SAYAH et al., 2005). A resistência a esse antimicrobiano é mediada por plasmídeos, queapresentamuma amplavariedadede determinantes genéticos. Estudos demonstraramque bactérias do solo ao adquirir resistência à tetraciclina quando exposta ao ambiente atua como reservatório deresistência aos animais hospedeiros (RYSZ; ALVAREZ, 2004; SAYAH et al., 2005).

Resistência às quinolonas, como o ciprofloxacino $(4,7 \%)$ e o ácido nalidíxico $(9,3 \%)$ (Tabela 1$)$, não tem sido associada à transferência gênica, mas à expressão de uma capacidade intrínseca da E. coli em desenvolver resistência quando exposta a um ambiente com pressão seletiva. Essa pressão pode ser exercida por qualquer uma das quinolonas ou fluoroquinolonas, resultando em resistência a todo o grupo (WebBer; Piddock, 2001, Silva et al., 2008). O ciprofloxacino é uma quinolona de segunda geração e a menor resistência observada ocorre porque essa droga se equivale as quinolonas de terceira geração e à sua potencia mais diferenciada, principalmente contra enterobactérias e pseudomonas (TAVARESetal., 2009). Comportamento semelhante foi relatado por SCHNEIDER et al. (2009), ao observarem maior resistência aoácido nalidíxico $(25,9 \%)$ do que o ciprofloxacino $(1,95 \%)$ em isolados de E. coli provenientes de águas subterrâneas e superficiais.

Resistência microbiana em organismos que não são considerados patógenos primários é de suma importância, principalmente para aqueles que carregam o plasmídeo $\mathrm{R}$ de resistência, uma vez que a transferência desses entre linhagens taxonômicas próximas (FARs et al., 2005) cria uma variabilidade genética sobre a qual atua a seleção natural, dando vantagens aos mais aptos (MотA et al., 2005).
Quando avaliado o perfil de suscetibilidade das E. coli por grupos de antimicrobianos usados ( $\beta$-lactâmicos, tetraciclinas, quinolonas, nitrofuranos e sulfonamidas), somente aos $\beta$-lactâmicos as cepas não apresentaram resistência (Tabela 1). Os bacilos gram-negativos entéricos são, na atualidade, amplamente resistentes aos antimicrobianos tradicionalmente ativos, tais como sulfonamidas, a ampicilina, cefalosporinas de terceira geração efluoroquinolonas (TAVARES, 2009). A susceptibilidade das cepas de $E$. coli aos betalactâmicos é satisfatória uma vez que este grupo de drogas tem sido o mais utilizado no controle de doenças infecciosas.

Resistência às quinolonas (ácido nalidixíco e o ciprofloxacino) tem emergido como um importante problema de saúde pública, resultante da sua livre utilização na aquicultura e nos processos industriais de produção animal (JACOBY, 2005).

Com relação ao perfil de multirresistência, foi observado que $21 \%$ dos isolados apresentaram resistência a uma combinação de agentes antimicrobianos incluindo a tetraciclina $(89 \%)$, sugerindo que a utilização de determinados agentes antimicrobianos, principalmente de amplo espectro de ação, contribui para o aparecimento de resistência (MotA et al., 2005). Monorresistência foi observada apenas para tetraciclina (21\%) e sulfazotrin $(7 \%)$. De acordo com a literatura, há um aumento de multirresistência entre as cepas de $E$. coli isoladas de vários ecossistemas (OufDou et al., 1999; FARS et al., 2005). CARDONHA et al. (2004), avaliando o perfil de resistência de cepas isoladas em diferentes praias na cidade de Natal, RN, observaram que $35,9 \%$ das E. coli apresentavam-se resistentes a um ou mais antimicrobianos.

Os resultados do índice MAR (Múltipla Resistência a Antimicrobianos) para os 43 isolados mostraram que $9(21 \%)$ cepas apresentaram índice MARigual ou superior a $25 \%$, ou seja, resistência associada a dois ou mais dos oito antimicrobianos testados (Tabela 2). O elevado índice de resistência encontrada está ligado a fenômenos de pressão seletiva, que atuariam favorecendo a instalação, manutenção e propagação de características de resistência entre as populações bacterianas no ambiente aquático (BELDA JuNIOR et al., 2005; HiRsch et al., 2006).

Quando avaliado se o perfil de multirresistência das amostras testadas era devido a mutações cromossômicas ou plasmidial observou-se que, para algumas cepas, a resistência à tetraciclina (38\%), ácido nalidixico (50\%), nitrofuratoina $(100 \%)$ e sulfazotrim (14\%) foi plasmidial (Tabela 2). Segundo CARNEIRO et al. (2007), os plasmídeos podem carrear determinantes de resistência simultânea a várias drogas, levando ao fenômeno de seleção cruzada e aumentando o número de bactérias multirresistentes em determinado ambiente. 
Tabela 1 - Percentual de suscetibilidade antimicrobiana de Escherichia coli, isoladas da água do açude Santo Anastácio (Fortaleza, CE).

\begin{tabular}{|c|c|c|c|c|c|c|}
\hline \multirow{2}{*}{ Grupos de antibióticos } & \multicolumn{2}{|c|}{ Resistente } & \multicolumn{2}{|c|}{ Intermediário } & \multicolumn{2}{|c|}{ Sensível } \\
\hline & $\mathrm{n}$ & $\%$ & $\mathrm{n}$ & $\%$ & $\mathrm{n}$ & $\%$ \\
\hline \multicolumn{7}{|l|}{ Betalactâmicos } \\
\hline - Ampicilina & 0,0 & 0,0 & 0,0 & 0,0 & 43 & 100 \\
\hline - Cefoxitina & 0,0 & 0,0 & 0,0 & 0,0 & 43 & 100 \\
\hline - Imipenem & 0,0 & 0,0 & 0,0 & 0,0 & 43 & 100 \\
\hline \multicolumn{7}{|l|}{ Tetraciclina } \\
\hline - Tetraciclina & 11,0 & 25,6 & 1,0 & 2,3 & 31 & 72,1 \\
\hline \multicolumn{7}{|l|}{ Quinolonas } \\
\hline - Ac. nalidixico & 4,0 & 9,3 & 0,0 & 0,0 & 39 & 90,7 \\
\hline - Ciprofloxacino & 2,0 & 4,7 & 0,0 & 0,0 & 41 & 95,3 \\
\hline \multicolumn{7}{|l|}{ Nitrofuranos } \\
\hline - Nitrofurantoina & 0,0 & 0,0 & 1,0 & 2,3 & 42 & 97,7 \\
\hline Sulfonamidas & & & & & & \\
\hline - Sulfazotrim & 8,0 & 18,6 & 0,0 & 0,0 & 35,0 & 81,4 \\
\hline
\end{tabular}

Tabela 2 - Índice de múltipla resistência a antimicrobianos (MAR) e perfil de resistência plasmidial de Escherichia coli isoladas da água do açudeSanto Anastácio (Fortaleza, CE).

\begin{tabular}{lccc}
\hline Cepa & Antimicrobianos & $\begin{array}{c}\text { MAR } \\
(\%)\end{array}$ & $\begin{array}{c}\text { Resistência } \\
\text { plasmidial }\end{array}$ \\
\hline 4 & TET, SUF & 25 & TET \\
9 & TET, CIP, SUF, NAL & 50 & - \\
28 & NIT, TET & 25 & NIT, TET \\
33 & TET, NAL & 25 & NAL \\
35 & TET, CIP, SUF, NAL & 50 & - \\
36 & TET, SUF & 25 & TET \\
38 & SUF, NAL & 25 & SUF, NAL \\
43 & TET, SUF & 25 & - \\
\hline
\end{tabular}

Nos isolados com índice MAR de 50\% (duas cepas), a resistência ocorreu de forma cromossomial, uma vez que essa característica não foi perdida. Ambas apresentaram resistência à tetraciclina. AKORTHA; EgbuLE (2008) também relataram resistência à tetraciclina mediada por cromossomo. A resistência cromossômica depende de mutação espontânea, embora seja raro; ela é dirigida quase sempre a uma só droga e os genes transferidos com frequência relativamente baixa, apresentam impacto clínico menor que o da resistência plasmidial. No presente estudo constatou-se que a resistência cromossômica esteve relacionada a duas ou mais drogas. Além disso, bactérias sensíveis podem receber genes cromossômicos mutantes de bactérias já resistentes, através dos processos de transformação, conjugação e transdução (AlterTHum, 2008).

A presença de linhagens de E. coli resistentes a antimicrobianos é preocupante por dificultar o tratamento de doenças em animais e humanos, agravando os quadros clínicos curáveis (МотA et al., 2005). Desta forma, a abordagem da resistência aos antimicrobianos constitui um dos parâmetros para definir o grau de importância de uma linhagem bacteriana associada a uma patologia (VON BAUM; MARRE, 2005), devendo-se estabelecer melhores critérios para a qualidade da água quanto à presença de $E$. coli através de monitoramento constante dos corpos d'água.

\section{CONCLUSÃO}

Os resultados obtidos apontam as águas do açude Santo Anastácio como reservatório na disseminação de estirpes de E. coli com elevado grau de resistência a diversos antimicrobianos, principalmente à tetraciclina. A presença de bactérias com perfil de multirresistência demonstra a necessidade da adoção de medidas que controlem a disseminação de genes de resistência visando à redução na sua circulação.

\section{REFERÊNCIAS}

AKORTHA, E.E.; EGBULE, O.S. Transfer of tetracycline resistance gene (tetr) between replicons in some enteric bacteria of diarrhoeal origin from some hospitals in South-South, Nigeria. African Journal of Biotechnology, v.7, n.18, p.3178-3181, 2008.

ALTERTHUM, F. Mecanismo de ação dos antibacterianos e mecanismos de resistência. In: TRABULSI, L. R.; ALTERTHUM, F. (Org.). Microbiologia. São Paulo: Atheneu, 2008. v.1, p.67-84.

AMARAL, L.A.; NADER FILHO, A.; ROSSI JUNIOR, O.D.; FERREIRA, F.L.A.; BARROS, L.S.S. Água de consumo humano como fator de risco à saúde em propriedades rurais. Revista de Saúde Pública, v.37, n.4, p.37-40, 2003. 
AMARAL, L.A.; ROSSI JUNIOR, O.D.; SOARES, E.; BARROS, L.S.; LORENZON, C.S.; NUNES, A.P. Tratamento Alternativo da Água Utilizando Extrato de Semente de Moringa Oleifera e Radiação Solar. Arquivos do Instituto Biológico, São Paulo, v.73, n.3, p.287-293, 2006.

BAQUERO, F.; MARTINEZ, J.L.; CANTON, R. Antbiotics and antibiotic resistance in water environments. Current Opinion in Biotechnology, v.19, p.260-265, 2008.

BELDA JUNIOR., W.; FAGUNDES, L.J.; SIQUEIRA, L.F.G. Neisseria gonorrhoeae: resistência cromossômica à tetraciclina em São Paulo, Brasil. Anais Brasileiros de Dermatologia, v.80, n.1, p.37-40, 2005.

BOON, P.I.; CATTANACH, M. Antibiotic resistance of native and faecal bacteria isolated from rivers, reservoirs and sewage treatment facilities in Victoria, southeastern Australia. Letters in Applied Microbiology, v.28, p.164-168, 1999.

CARDONHA, A.M.S.; VIEIRA, R.H.S.F.; RODRIGUES, D.P.; MACRAE, A.; PEIRANO, G.; TEOPHILO, G.N.D. Fecal pollution in water from storm sewers and adjacent seashores in Natal Rio Grande do Norte, Brazil. International Microbiology, v.7, p.213-218, 2004.

CARNEIRO, D.O.; H.C.P. FIGUEIREDO, H.C.P.; PEREIRA JÚNIOR, D.J.; LEAL, C.A.G; LOGATO, P.V.R. Perfil de susceptibilidade a antimicrobianos de bactérias isoladas em diferentes sistemas de cultivo de tilápia-do-nilo (Oreochromis niloticus). Arquivo Brasileiro de Medicina Veterinária e Zootecnia, v.59, n.4, p.869-876, 2007.

CLSI: Clinical and Laboratory Standards Institute. Performance standards for antimicrobial susceptibility testing: seventeenth informational supplement. Wayne: CLSI, 2007. (CLSI Document M100-S17).

ESTEVES, F.A. (Ed.) Ecologia das Lagoas Costeiras do Parque Nacional da Restinga de Jurubatiba e do Município de Macaé $(R J)$. Rio de Janeiro: Universidade Federal do Rio de Janeiro, 1998. 464p.

FARS, S.; OUFDOU, K.; NEJMEDDINE, A.; HASSANI, L.; MELLOUL, A.A.; BOUSSELHAJ, K.; AMAHMID, O.; BOUHOUM, K.; LAKMICHI, H.; MEZRIOUI, N. Antibiotic resistance and survival of faecal coliforms in activated sludge system in a semi-arid region (Beni Mellal, Morocco). World Journal of Microbiology and Biotechnology, v.21, p.493-500, 2005.

FUENTEFRIA, D.B.; FERREIRA, A.E.; GRAF, T.; CORÇÃO, G. Pseudomonas aeruginosa: disseminação de resistência antimicrobiana em efluente hospitalar e água superficial. Revista da Sociedade Brasileira de Medicina Tropical, v.4, n.5, p.470-473, 2008.

HIRSCH, D.; PEREIRA JUNIOR, D.J.; LOGATO, P.V.R.; PICCOLI, R.H.; FIGUEREIDO, H.C.P. Identificação e resistência a antimicrobianos de espécies de Aeromonas móveis isoladas de peixes e ambiente aquáticos. Ciência Agrotécnica, v.30, n.6, p.1211-1217, 2006.

JACOBY, G.A. Mechanisms of resistance to quinolones. Clinical Infection Diseases, v.41, p.S120-S126, 2005. Supplement 2.

KUMMERER, K. Significance of antibiotics in the environment. Journal of Antimicrobial Chemotherapy, v.52, p.5-7, 2003.

MARTINHAGO, M.W.; BUZANELLO, E.B.; ALMEIDA, M.M.; PINTO, F.G.S. Avaliação do perfil de susceptibilidade das cepas de Escherichia coli isoladas da água do lago municipal de Cascavel, Paraná. Revista Brasileira de Biociências, v.6, p.62-62, 2008. Suplemento 1.

MEHLMAN, I.J.; ANDREWS, W. I.I.; WENTZ, V.A. Coliform bacteria. In: ASSOCIATION OF OFFICIAL ANALYTICAL CHEMISTS. Bacteriological analytical manual. 6.ed. Arlington: AOAC, 1984. p.5.01-5.07.

MEIRELLES-PEREIRA, F.; PEREIRA, A.M.S.; SILVA, M.C.G.; GONÇALVES, V.D.; BRUM, P.R.; CASTRO, E.A.R.; PEREIRA, A.A.; ESTEVES, F.A.; PEREIRA, J.A.A. Ecological aspects of the antimicrobial resistance in bacteria of importance to human infections. Brazillian Journal of Microbiology, v.33, p.287-293, 2002.

MELO, S.K. Caracterização de fatores de virulência em amostras de Escherichia coli isoladas de lagoas do Parque Estadual do Rio Doce - MG. 2006. 100f. Dissertação (Mestrado em Engenharia Ambiental) - Curso de Engenharia Ambiental da Escola de Minas, Universidade Federal de Ouro Preto, Ouro Preto, 2006.

MOLINA-AJA, A.; GARCÍA-GASCA, A.; ABREU-GROBOIS, A.; BOLÁN-MEJÍA, C.; ROQUE A.; GOMEZ-GIL, B. Plasmid profiling and antibiotic resistance of Vibrio strains isolated from cultured penaeid shrimp. FEMS Microbiology Letters, v.213, p.7-12, 2002.

MOTA, R.A.; SILVA, K.P.C.; FREITAS, M.F.L.; PORTO, W.J.N.; SILVA, L.B.G. Utilização indiscriminada de antimicrobianos e sua contribuição a multirresistência bacteriana. Brazilian Journal of Veterinary Research and Animal Science, v.42, n.6, p.465-470, 2005.

MOURA, A.C.; ASSUMPÇÃO, R.A.B.; BISCHOFF, J. Monitoramento físico-químico e microbiológico da água do rio cascavel durante o período de 2003 a 2006. Arquivos do Instituto Biológico, São Paulo, v.76, n.1, p.17-22, 2009. Disponível em: <http://www.biologico.sp.gov. br/docs/arq/v76_1/moura.pdf $>$. Acesso em: 13 jun. 2009.

NIJSTEN, R.; LONDON, N.; BOGAARD, A. \& STOBBERINGH, V.D. Antibiotic resistance of enterobacteriaceae isolated from the faecal flora of fattening pigs. Veterinary Quarterly, v.15, n.4, p.152-157, 1993. 
OUFDOU, K.; MEZRIOUI, N.; MELLOUL, A.A;

BARAKATE, M.; ALLA, A.A. Effects of sunlight and Synechocystis sp. (picocyanobacterium) on the incidence of antibiotic resistance in wastewater enteric bacteria. World Journal of Microbiology and Biotechnology, v.15, p.553-559, 1999.

PEAK, N.; KNAPP, C.W.; YANG, R.K.; HANFELT, M.M.; SMITH, M.S.; AGA, D.S.; GRAHAM, D.W. Abundance of six tetracycline resistance genes in wastewater lagoons at cattle feedlots with different antibiotic use strategies. Environmental Microbioliology, v.9, p.143-151, 2007.

RYSZ, M.; ALVAREZ, P.J.J. Amplification and attenuation of tetracycline resistance in soil bacteria: aquifer column experiments. Water Research, v.38, p.3705-3712, 2004.

SAYAH, R.S.; KANEENE, J.B.; JOHNSON, Y.; MILLER, R. Patterns of Antimicrobial Resistance Observed in Escherichia coli Isolates Obtained from Domestic- and Wild-Animal Fecal Samples, Human Septage, and Surface Water. Applied and Environmental Microbiology, v.71, n.3, p.1394-1404, 2005.
SCHNEIDER, R.N.; NADVORNY, A.; SCHMIDT, V. Perfil de resistência antimicrobiana de isolados de Escherichia coli obtidos de águas superficiais e subterrâneas, em área de produção de suínos. Biotemas, v.22, n.3, p.11-17, 2009.

SILVA, F.F.P.; SANTOS, M.A.A.; SCHMIDT, V. Resistência a antimicrobianos de Escherichia coli isolada de dejetos suínos em esterqueiras. Arquivo Brasileiro de Medicina Veterinária e Zootecnia, v.60, n.3, p.762-765, 2008.

TAVARES, W. Antibióticos e quimioterápicos para o clínico. 2.ed. São Paulo: Atheneu, 2009. 599p.

VIEIRA, R.H.S.F. Microbiologia, Higiene e Qualidade do Pescado. São Paulo: Varela, 2004. 380p.

VIEIRA, R.H.S.F.; FAÇANHA, S.H.F. Parâmetros físicoquímicos, pesquisa de coliformes totais e fecais e Vibrio parahaemolyticus nas águas do Rio Cocó, Fortaleza-Ceará. Revista Ciência Agronômica, v.25, p.24-31, 1994.

Recebido em 2/6/09

Aceito em 21/7/10 